\title{
Voids in Kesterites and the Influence of Lamellae Preparation by Focused Ion Beam for Transmission Electron Microscopy Analyses
}

\author{
Rodrigo Ribeiro-Andrade, Sylvester Sahayaraj, Bart Vermang, M. Rosario Correia ${ }^{\mathbb{\infty}}$, Sascha Sadewasser, \\ Juan Carlos González ${ }^{\circledR}$, Paulo A. Fernandes, and Pedro M. P. Salomé ${ }^{\mathbb{1}}$
}

\begin{abstract}
Kesterite solar cells based on $\mathrm{Cu}_{2} \mathrm{ZnSnS}_{4}$ and $\mathrm{Cu}_{2} \mathrm{ZnSnSe}_{4}$ (CZTSe) are potential future candidates to be used in thin-film solar cells. The technology still has to be developed to a great extent and for this to happen, high levels of confidence in the characterization methods are required, so that improvements can be made on solid interpretations. In this study, we show that the interpretations of one of the most used characterization techniques in kesterites, scanning transmission electron microscopy (STEM), might be affected by its specimen preparation when using focused ion beam (FIB). Using complementary measurements based on
\end{abstract}

Manuscript received June 6, 2018; revised August 8, 2018, September 21, 2018, and December 4, 2018; accepted December 20, 2018. Date of publication January 11, 2019; date of current version February 18, 2019. This work was supported in part by the FEDER funds through the COMPETE 2020 Programme, in part by FCT-Portuguese Foundation for Science and Technology under Project UID/CTM/50025/2013, in part by CAPES (CAPES-INL 04/14), in part by FAPEMIG, and in part by CNPq Brazilian agencies. The work of B. Vermang was supported by the European Research Council under the European Union's Horizon 2020 Research and Innovation Programme under Grant Agreement 715027. The work of P. M. P. Salomé was supported in part by the Fundação para Ciência e Tecnologia (FCT) under Project IF/00133/2015 and in part by the NovaCell-Development of Novel Ultrathin Solar Cell Architectures for Low-Light, Low-Cost, and Flexible Opto-Electronic Devices Project (028075) co-funded by FCT and the ERDF under Grant COMPETE2020. (Corresponding author: Pedro M. P. Salomé.)

R. Ribeiro-Andrade is with the International Iberian Nanotechnology Laboratory, Braga 4715-330, Portugal, and also with the Departamento de Física, Universidade Federal de Minas Gerais, Belo Horizonte 30123-970, Brazil (e-mail: rodrigo.ribeiro@visitor.inl.int).

S. Sahayaraj is with Imec-Partner in Solliance, Leuven 3001, Belgium (e-mail: Sylvester.Sahayaraj@imec.be).

B. Vermang is with Imec-Partner in Solliance, Leuven 3001, Belgium, with Imomec-Partner in Solliance, Diepenbeek 3590, Belgium, and also with the University of Hasselt-Partner in Solliance, Diepenbeek 3590, Belgium (e-mail: bart.vermang@imec.be).

M. R. Correia is with the Departamento de Física, Universidade de Aveiro, Aveiro 3810-193, Portugal, and also with the I3N, Universidade de Aveiro, Aveiro 3810-193, Portugal (e-mail: mrcorreia@ua.pt).

S. Sadewasser is with the International Iberian Nanotechnology Laboratory, Braga 4715-330, Portugal (e-mail: sascha.sadewasser@inl.int).

J. C. González is with the Departamento de Física, Universidade Federal de Minas Gerais, Belo Horizonte 30123-970, Brazil (e-mail: gonzalez@ fisica.ufmg.br).

P. A. Fernandes is with the International Iberian Nanotechnology Laboratory, Braga 4715-330, Portugal, with the I3N, Universidade de Aveiro, Aveiro 3810-193, Portugal, and also with the CIETI, Departamento de Física, Instituto Superior de Engenharia do Porto, Instituto Politécnico do Porto, Porto 4200-072, Portugal (e-mail: paulo.fernandes@inl.int).

P. M. P. Salomé is with the International Iberian Nanotechnology Laboratory, Braga 4715-330 Portugal, and also with I3N, Universidade de Aveiro, Aveiro 3810-193, Portugal (e-mail: pedro.salome@inl.int).

Color versions of one or more of the figures in this paper are available online at http://ieeexplore.ieee.org.

Digital Object Identifier 10.1109/JPHOTOV.2018.2889602 scanning electron microscopy and Raman scattering spectroscopy, compelling evidence shows that secondary phases of $\mathrm{ZnSe}$ mixed in the bulk of CZTSe are the likely cause of the appearance of voids in STEM lamellae. Sputtering simulations support this interpretation by showing that $\mathrm{Zn}$ in a $\mathrm{ZnSe}$ matrix is preferentially sputtered compared with any metal atom in a CZTSe matrix.

Index Terms- $\mathrm{Cu}_{2} \mathrm{ZnSn}(\mathrm{S}, \mathrm{Se})_{4}$ (CZTSSe), focused ion beam (FIB), kesterite, thin-film solar cells, transmission electron microscopy (TEM).

\section{INTRODUCTION}

$\mathbf{T}$ $\mathrm{HE}$ semiconductor $\mathrm{Cu}_{2} \mathrm{ZnSn}(\mathrm{S}, \mathrm{Se})_{4}$ (CZTSSe), with kesterite crystalline structure, is currently studied as the absorber layer in thin-film solar cells. The biggest selling point of the CZTSSe compound has been the use of abundant materials like $\mathrm{Cu}, \mathrm{Zn}$, and $\mathrm{Sn}$ [1]. Some other advantages of the CZTSSe compound are: its tuneable bandgap energy from $\sim 1$ [2], [3] to $1.5 \mathrm{eV}$ [4] (by replacing Se by S); the high value of optical absorption [5], [6]; the use of a solar cell structure similar to the one of $\mathrm{Cu}(\mathrm{In}, \mathrm{Ga}) \mathrm{Se}_{2}$ [7], [8]; some doping properties can be achieved by diffusion of alkalis from the glass [9]; the flexibility in having several methods capable of synthetizing the compound [10]-[18]; just to name a few. In spite of these advantages, the maximum power conversion efficiency of a CZTSSe laboratory solar cell is just around $12.6 \%$ [19]. Such limited efficiency has been attributed to a few issues which significantly limit the open circuit voltage $\left(V_{\mathrm{oc}}\right)$ : secondary phases [20]-[25]; poor band alignments and cell architecture problems [15], [16], [26], [27]; high values of fluctuating potentials [28][31]; and a kesterite/stannite crystal mixture [32]-[34]. Among all these issues, secondary phases have been intensively studied as they form easily [23], [35]-[37] and are detrimental from an electrical point of view. Raman spectroscopy, X-ray diffraction (XRD), and scanning transmission electron microscopy (STEM) are the most frequently used techniques to identify these spurious phases. In particular, STEM analysis is quite relevant as it allows for an evaluation of the morphology, crystallinity, and of the sample's elemental composition (by energy-dispersive $\mathrm{X}$-ray spectroscopy-EDS). Commonly, the preparation of the STEM lamellae is done either by a combination of mechanical and $\mathrm{Ar}^{+}$ion polishing or by milling with $\mathrm{Ga}^{+}$focused ion beam (FIB). State-of-the-art FIB tools are capable of sample preparation with the advantage of fast and precise milling of 
the lamellae, with very limited damage to the lamellae surface by finishing the milling with low ion beam energy $(0.5-2 \mathrm{keV})$. However, even in these cases, the ion milling process might create artifacts in some material systems.

In this paper, we present a study showing that the preparation of STEM specimens by using FIB sample preparation might lead to the appearance of artifacts in the STEM characterization of $\mathrm{Cu}_{2} \mathrm{ZnSnSe}_{4}$ (CZTSe) samples. There is evidence that voids in the lamellae observed in STEM analysis could be artifacts created by the presence of $\mathrm{ZnSe}$ secondary phases in the CZTSe sample. We use a combination of STEM, Raman spectroscopy, scanning electron microscopy (SEM), and sputtering simulations to support these findings.

\section{EXPERIMENTAL}

Solar cells were fabricated on a 3-mm-thick, $25-\mathrm{cm}^{2}$ soda lime glass (SLG) substrate covered by $400 \mathrm{~nm}$ of molybdenum (Mo) as electrical back contact. Metallic precursors were sequentially deposited using e-beam evaporation and selenized at $460{ }^{\circ} \mathrm{C}$ in a Se-rich atmosphere to form the CZTSe layer as described elsewhere [38]. This particular set of samples had a 100-nm-thick $\mathrm{SiO}_{2}$ layer sputtered on top of the SLG to prevent alkali diffusion [9]. The CZTSe absorbers were then finished into solar cells with a CdS layer deposited by chemical bath deposition and a transparent conductive oxide constituted by $\mathrm{i}-\mathrm{ZnO}$ and $\mathrm{ZnO}: \mathrm{Al}$. The final solar cell structure was: $\mathrm{SLG} / \mathrm{SiO}_{2} / \mathrm{Mo} / \mathrm{CZTSe} / \mathrm{CdS} / \mathrm{i}-\mathrm{ZnO} / \mathrm{ZnO}: \mathrm{Al}$ and the device studied here had a power conversion efficiency of $5.3 \%$. We note that on top of Mo, a layer of $\mathrm{MoSe}_{2}$ is usually formed [39].

STEM images were taken with an FEI Titan ChemiThemis 80-200 kV Cs-probe corrected transmission electron microscope, operating at 200-kV accelerating potential and equipped with electron Bruker EDS SuperX detector. In this method, a coherent focused probe scans across the specimen and the $\mathrm{X}$ ray emission spectrum is recorded in each probe position. All samples studied in the cross-sectional mode were prepared in a FIB FEI Dual-Beam Helios $450 \mathrm{~S}$ with FIB lift-out Mo-grids using a technique known as "lift-out" [40]. On top of the solar cell, we deposit a carbon layer to reduce the charging effect that displaces the electron/ion beam during the Pt bi-layer deposition. The $\mathrm{Pt}$ deposition assisted by the electron and the $\mathrm{Ga}$ beam serves to reduce the vertical ripples (either curtain effect or waterfall effect) [41]-[43] due to changes in the sputter yield and angle of incidence as the ion beam passes over a step, pore, local curvature, or regions of different compositions. The lamella ion-milling, i.e., the polishing process, was done using a $\mathrm{Ga}^{+}$beam with $30-15-2-1 \mathrm{kV}$ polishing steps to thin down the lamella and final polishing energy of $1 \mathrm{kV}$ to minimize lamella surface damage. SEM images were taken with a high-resolution NovaNanoSEM 650 SEM system. Raman scattering experiments were carried out at room temperature using a Jobin-Yvon LabRaman HR800 spectrometer equipped with a multi-channel Peltier-cooled charge-coupled device detector, in the backscattering geometry, and using a 442-nm excitation wavelength. The sample surface was focused with an objective of $50 \times($ numerical aperture $=0.50$; working distance $=$ $10.6 \mathrm{~mm}$ ), and the incident power was varied from 70 to $790 \mu \mathrm{W}$.

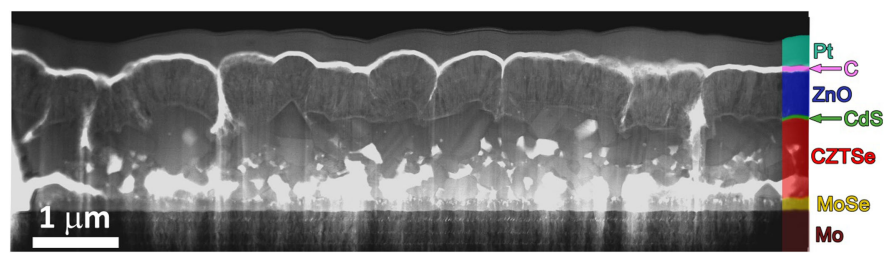

Fig. 1. STEM BF image of the cross section of a CZTSe solar cell. The white spots are voids in the CZTSe film, whereas the top continuous white layer is the protective carbon coating.

\section{RESULTS}

A bright field (BF) cross-sectional image of the CZTSe lamella is shown in Fig. 1. The image shows, from bottom to top, the Mo rear electrode (deposited with four layers), an $\mathrm{MoSe}_{2}$ layer, the CZTSe absorber, the CdS buffer layer, the $\mathrm{ZnO}$ transparent conductive layers, a thin and bright protective carbon layer, and then another protective Pt layer deposited by the FIB. In STEM BF images, bright areas either correspond to very low mass density regions (e.g., the protective carbon layer) or to voids/empty spaces where the lamella is highly transparent to the incoming beam. That is the case of the low mass density protective carbon layer. The $\mathrm{ZnO}$ layer presents some vertical white segments, corresponding to either cracks or pin-holes in the film. Other bright areas or pin-holes can be observed in the CZTSe layer. The identification of such pinholes is important as they are detrimental from a device point of view. The observation of voids in the growth of kesterite materials is something that is common and it has been attributed mostly to Kirkendall effects during the chalcogenation process [44]-[46] and to complex thermodynamic reactions taking place at the Mo interface [47]. As such, the voids seen in the literature have the tendency to be present close to the back contact. In our case, although voids are present close to the Mo interface, they are also present, to some extent, throughout the whole thickness of the CZTSe layer.

To validate the presence of the voids and to analyze the sample elemental distribution, we performed high-angle annular dark field (HAADF) imaging and EDS analysis. Fig. 2(a) shows a HAADF image of the same region of the lamella. The voids and the protective carbon layer now show a dark contrast. EDS mappings for $\mathrm{Sn}, \mathrm{Cu}, \mathrm{Zn}, \mathrm{Se}, \mathrm{Cd}$, and $\mathrm{S}$ for the same region are also presented. $\mathrm{Cu}$ and $\mathrm{Sn}$ are distributed equally inside the CZTSe but not uniformly, as there are spots with no counts. For the $\mathrm{Zn}$ and Se EDS maps, we can still see dark areas, corresponding to voids. There is also a high intensity of $\mathrm{Zn}$ and Se signals close to the voids. The high concentration of $\mathrm{Zn}$ in the top layers corresponds to the $\mathrm{ZnO}$ layer. In the CZTSe layer, a bright spot in the BF image (or dark in the HAADF image) could be related both with a void or with a lower atomic number phase like $\mathrm{ZnSe}$, since $\mathrm{Sn}(\mathrm{Z}=50)$ is a much heavier element than $\mathrm{Cu}(\mathrm{Z}=29), \mathrm{Zn}(\mathrm{Z}=30)$, and Se $(Z=34)$. Thus, a ZnSe region would appear as a much lighter elemental region than a $\mathrm{Cu}_{2} \mathrm{SnZnSe}_{4}$ region. The EDS analysis shows that parts of the dark regions in the HAADF image are indeed $\mathrm{Zn}$-rich areas, and it also shows that close to these regions, there are areas with no EDS signal of any element, confirming the presence of voids. The non-uniform distribution of $\mathrm{Zn}$ and $\mathrm{Se}$ with the presence of 

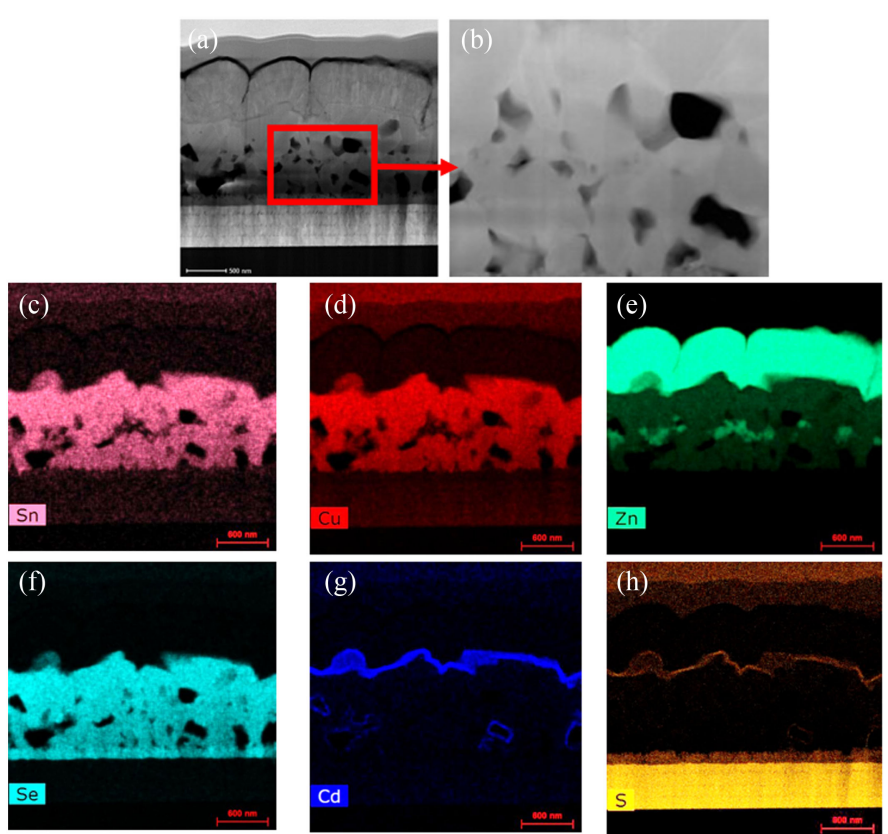

Fig. 2. (a) and (b) HAADF image and corresponding STEM-EDS maps for (c) $\mathrm{Sn}$, (d) $\mathrm{Cu}$, (e) $\mathrm{Zn}$, (f) $\mathrm{Se}$, (g) Cd, and (h) S. The analysis confirms voids in the sample with a slight enrichment of $\mathrm{ZnSe}$ in adjacent regions. The high concentration of $\mathrm{S}$ at the back contact is due to superimposition with Mo.

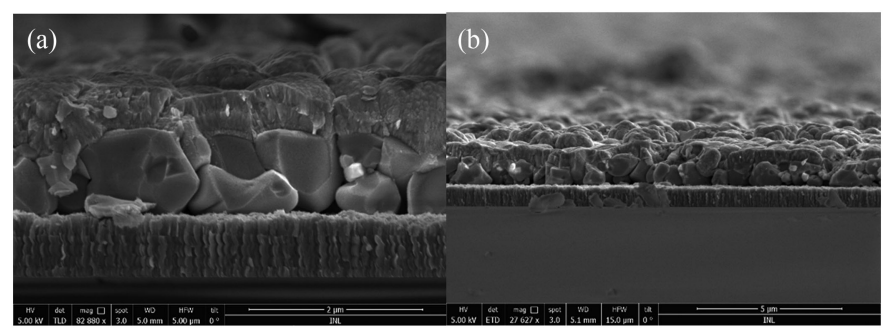

Fig. 3. High- and low-magnification SEM images of the cross section of the CZTSe solar cell.

ZnSe aggregates close to the voids is the first indication that the two events can be to a certain degree correlated. Furthermore, the EDS analysis also shows that a small number of visible voids are surrounded by $\mathrm{Cd}$ and $\mathrm{S}$, suggesting a layer of $\mathrm{CdS}$. This fact can be explained by these specific voids being already present during the chemical bath deposition of the CdS layer. On the voids where $\mathrm{Cd}$ and $\mathrm{S}$ are present, the concentration of $\mathrm{Zn}$ is similar to the rest of the film. Hence, this analysis reveals the possibility of two different types of voids: i) voids that were already present at the sample preparation stage and that were identified by being coated by a CdS layer; ii) voids that are close to the segregation of $\mathrm{ZnSe}$ aggregates. In the rest of the paper, we will focus our attention on the second type of voids, i.e., the ones in the vicinity of $\mathrm{ZnSe}$ aggregates.

To verify if the voids that are not coated in CdS are present in the samples prior to the FIB process, we prepared cross sections by cleaving the samples and performing SEM measurements. A representative image of the cross section is shown in Fig. 3. The image shows the same layers as previously but surprisingly, the
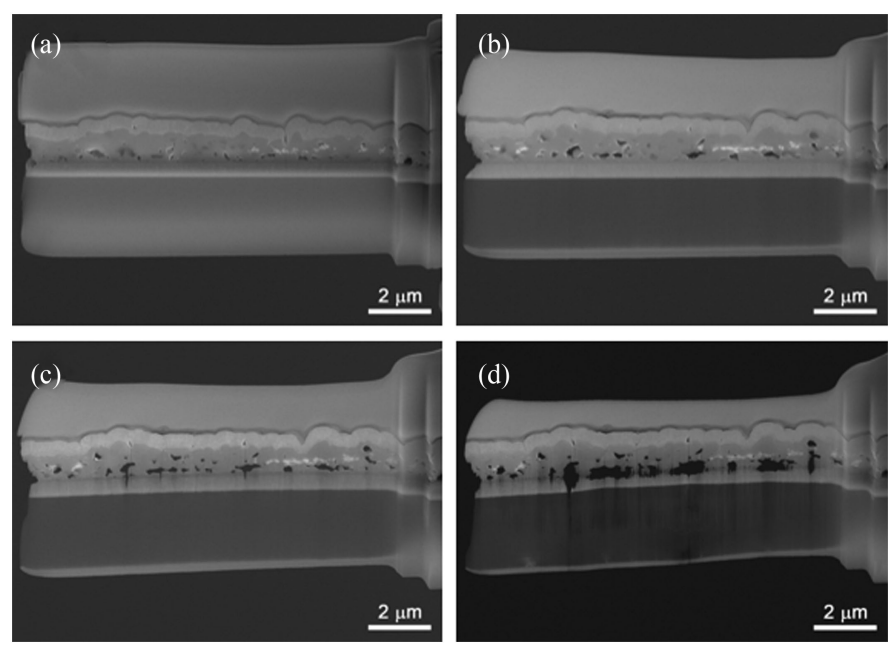

Fig. 4. Evolution of the lamella with the thinning-down process at several acceleration voltage stages. (a) and (b) Evolution during the $30-\mathrm{kV}$ stage, (c) after the $2-\mathrm{kV}$ stage, and (d) the final result after a $1-\mathrm{kV}$ polishing stage.

presence of voids, compared with the STEM images, is significantly reduced. A very small number of what might be voids is present close to the Mo interface. However, contrary to the STEM observations voids are only observed at the grain boundaries of the CZTSe grains. These large CZTSe grains present a dimension similar to the film thickness. Additionally, small grains around the middle of the film with a brighter contrast can be seen. The contrast difference suggests a different chemical composition in the bright grains. Even though the identification of voids using SEM is much more complex because of the fracture/cleavage process, this basic analysis indicates that the voids observed in the TEM analysis are not present prior to the FIB preparation.

As an additional evidence of the appearance of voids during the lamella preparation, in Fig. 4 we present, four SEM images that show the voids formation during the lamella thinning-down process for a second lamella prepared from the same CZTSe sample. After a $30-\mathrm{kV}$ thinning, some voids are already visible, as shown in Fig. 4(a). As discussed previously, some of these voids could already be present in the film. As the thinningdown process progresses, the images show the appearance of more voids as well as their increase in size even for the stages where a lower acceleration voltage is used [see Fig. 4(b)-(d)].

Additionally, we performed Raman scattering spectroscopy, as by XRD, CZTSe cannot be distinguished from ZnSe. The analysis was performed after a standard 1 minute $5 \% \mathrm{HCl} \mathrm{chem-}$ ical etch process to remove the $\mathrm{ZnO}$ layers and most of the $\mathrm{CdS}$, so that most of the absorber layer could be probed. The Raman spectra taken on the surface [Fig. 5(a)] show peaks at 174, 195, and $233 \mathrm{~cm}^{-1}$ corresponding to CZTSe, and at $300 \mathrm{~cm}^{-1}$ related to $\mathrm{CdS}$, the latter showing an incomplete etching process of the CdS layer. However, the Raman spectroscopy analysis is only capable of probing down to a few hundred nanometers from the top surface due to the high light absorption coefficient of CZTSe [20], [48]. Hence, we also performed an analysis on the cross section to probe the full thickness. This kind of analysis is quite 


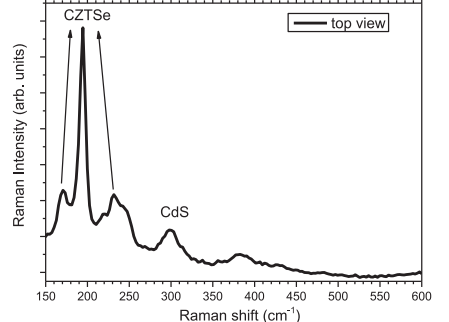

(a)

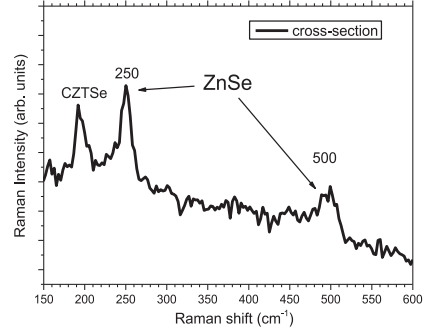

(b)
Fig. 5. Raman scattering spectroscopy analysis of the (a) surface and (b) cross section of a CZTSe sample. The surface measurement shows only the presence of CZTSe and CdS, whereas the cross section reveals the appearance of $\mathrm{ZnSe}$.
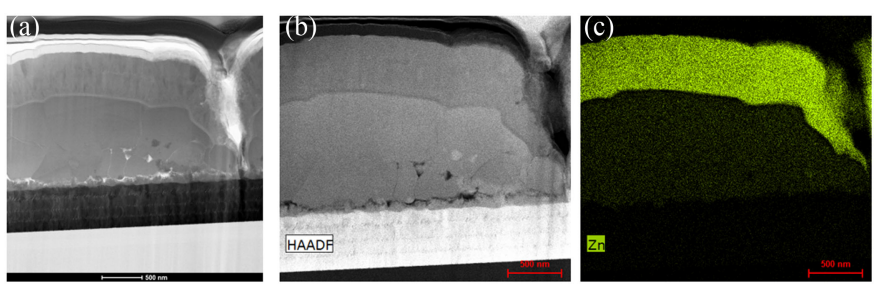

Fig. 6. (a) BF image of the cross section of a CZTSe solar cell with reduced number of secondary phases. (b) HAADF of the same area and (c) EDS mapping of $\mathrm{Zn}$ showing no segregation.

complex as the laser spot size is on the same order of magnitude as the film thickness itself, and thus, the volume probed is higher than the effective film volume with a compromise in signal to noise level. The results are shown in Fig. 5(b) confirming the presence of the CZTSe phase, as expected, but now ZnSe is also visible with peaks at 250 and $500 \mathrm{~cm}^{-1}$ [20]. The conjugation of both measurements allows us to conclude that $\mathrm{ZnSe}$ is present in the depth of the CZTSe film but not at the film's surface. Thus, the Raman spectroscopy analysis supports the EDS interpretation that the CZTSe sample has ZnSe segregates. It is also important to note that neither voids seen by the STEM nor ZnSe phases seen by Raman spectroscopy were identified at the surface of the sample. Hence, this is a further indication that the voids and the $\mathrm{ZnSe}$ segregates might be related.

To validate if the appearance of the voids could be related with Zn-rich segregates, a lamella of a second CZTSe solar cell fabricated with optimized conditions that minimize the appearance of secondary phases was prepared by FIB following the same protocol and analyzed similarly [49]. For this optimized fabrication process, the amount of secondary phases is smaller [49]. In Fig. 6, the BF image of the cross section is presented and, compared with the previous sample, the number of observable voids is dramatically reduced. The HAADF image confirms this observation. EDS mapping of Zn, shown in Fig. 6(c), shows no segregation. Hence, when there is a reduced number of $\mathrm{ZnSe}$ segregates, there is also a reduced number of voids in the TEM lamella.

Having demonstrated a correlation between the ZnSe aggregates in the EDS analysis close to the voids and the presence of ZnSe secondary phases in the bulk of the CZTSe absorber, we now provide for an explanation why the voids appear during the FIB lamella preparation. At this point, we note that the presence
TABLE I

AVErage Number of SPUTtered ATOMS When a Ga ION With ENERGy oF 30 AND 1 KV STRIKES A SOLID MiXTURE OF Zn, ZnSe, AND CZTSe

\begin{tabular}{|l|l|l|l|l|l|}
\hline & Compound & Zn & Se & Sn & Cu \\
\hline \hline \multirow{2}{*}{$\begin{array}{l}\text { Ga ion beam at } \\
30 \mathrm{kV}\end{array}$} & ZnSe & 23.4 & 15.0 & - & - \\
\cline { 2 - 6 } & CZTSe & 6.0 & 15.6 & 2.6 & 5.3 \\
\hline \multirow{2}{*}{$\begin{array}{l}\text { Ga ion beam at } \\
1 \mathrm{kV}\end{array}$} & ZnSe & 3.2 & 2.0 & - & - \\
\cline { 2 - 6 } & CZTSe & 0.8 & 2.1 & 0.3 & 0.8 \\
\hline
\end{tabular}

of $\mathrm{ZnSe}$ as a secondary phase is largely reported in the literature as it depends on the growth conditions of the CZTSe layer [50][52]. We simulated the sputtering yield of the different elements involved when a $30-\mathrm{kV}$ Ga ion beam is incident at a $3^{\circ}$ angle, to simulate the effects of the beam tail, using the Stopping and Range of Ions in Matter software. The results are summarized in Table I and, basically, in a solid mixture of $\mathrm{Cu}-\mathrm{Zn}-\mathrm{Sn}-\mathrm{Se}$ with $\mathrm{ZnSe}$, an incident $\mathrm{Ga}^{+}$beam with an energy of $30 \mathrm{kV}$ sputters away around four times more $\mathrm{Zn}$ if it hits $\mathrm{ZnSe}$ compared with the same beam hitting CZTSe. Thus, if a compound is constituted by a mixture of CZTSe and $\mathrm{ZnSe}$, a bombardment of $\mathrm{Ga}^{+}$ ions will sputter away $\mathrm{Zn}$ in the $\mathrm{ZnSe}$ phase four times more efficiently than Zn in the CZTSe phase. This observation is true both for 30 and $1 \mathrm{kV}$. It is then evident that during the FIB thinning-down process of the CZTSe lamella, the presence of a $\mathrm{ZnSe}$ secondary phase can lead to the appearance of voids as the $\mathrm{ZnSe}$ secondary phases are sputtered preferentially. While a realistic simulation of the lamella milling accounting for material re-deposition [53], ion beam tails [54] ion channeling [55], [56] and other [42], [43] issues that can influence the formation of voids is a very complicated task, our simple modeling fits and explains well the observed results. The exact reason why part of the ZnSe aggregates are sputtered away while some minor ZnSe phases stays close to the voids could be explained by a non-three-dimensional (3-D) uniformity of the phase distribution but again, these simulations are complex and it is intuitive to understand that a surface sputtering of a non-uniform 3-D thin film can lead to several effects.

\section{CONCLUSION}

In this paper, we identified two different types of voids seen in TEM lamellas. The first type of voids is natural occurring voids that are evenly coated by $\mathrm{CdS}$ during the chemical bath deposition and that are present in the early stages of the FIB preparation and in SEM cross-sectional images. These voids are usually attributed to Kirkendall effects [44]-[46]. The second type of voids, larger and present with a higher amount compared with the natural occurring voids, are the likely results of the FIB preparation of CZTSe TEM lamellae. In some cases, preparation of CZTS(Se)e thin films by FIB can exhibit preferential loss of $\mathrm{ZnSe}$ leading to void formation. Therefore, care needs to be exercised when analyzing composition and void formation mechanisms during processing of the films. The preferential loss of $\mathrm{ZnSe}$ is supported by several characterizations performed. First, an increased amount of ZnSe close to the voids was seen by the EDS analysis. Second, cross-sectional images 
taken during the thinning-down process clearly show an increase in both size and number of voids in the CZTSe film. Third, the void formation can be explained by simple sputtering simulations that show a preferential sputtering of $\mathrm{ZnSe}$ versus CZTSe, with four times higher sputtering efficiency for $\mathrm{ZnSe}$. Finally, a CZTSe sample that was intentionally optimized and prepared with a lower concentration of $\mathrm{ZnSe}$ secondary phases shows almost no voids. Hence, the observation of voids in kesterite samples using TEM analysis has to be taken with care if the preparation of the lamellae is done using FIB. In fact, several works found voids and local excess of $\mathrm{Zn}(\mathrm{S}, \mathrm{Se})$ [57]-[61], which are the main indications of the artifacts found in our study. TEM studies have to be paired with other analysis in order to have complementary data. A suggestion is to document the FIB thinning-down process with SEM images and EDS mapping, a process which, unfortunately, is very elaborate. We note that even for TEM specimen prepared with other means, the artifacts can also appear since most of them also use ion-based polishing steps. We note that the findings of this paper might not be universal for kesterites as many factors influence the sputtering process during the FIB preparation. Specifically, properties that are heavily influenced by the preparation method such as: grain boundaries and orientation; different types of segregations and secondary phases; elemental depth and lateral profiling; preexistence of other features as voids or differences in density. Hence, only a very complex analysis that would include the sample conditions would allow one to understand the full effect of the FIB sputtering on the sample preparation. However, the use of more advanced preparation techniques with either cryo steps or rocking approaches could also be a solution to the found artifacts.

\section{REFERENCES}

[1] J. J. Scragg, P. J. Dale, L. M. Peter, G. Zoppi, and I. Forbes, "New routes to sustainable photovoltaics: Evaluation of $\mathrm{Cu}_{2} \mathrm{ZnSnS}_{4}$ as an alternative absorber material," Phys. Status Solidi Basic Res., vol. 245, no. 9, pp. 1772-1778, 2008 .

[2] P. M. P. Salomé et al., "Growth pressure dependence of $\mathrm{Cu}_{2} \mathrm{ZnSnSe}_{4}$ properties," Sol. Energy Mater. Sol. Cells, vol. 94, no. 12, pp. 2176-2180, 2010.

[3] A. Walsh, S. H. Wei, S. Chen, and X. G. Gong, "Design of quaternary chalcogenide photovoltaic absorbers through cation mutation," in Proc. IEEE Photovolt. Spec. Conf., 2009, pp. 001875-001878.

[4] K. Sekiguchi, K. Tanaka, K. Moriya, and H. Uchiki, "Epitaxial growth of $\mathrm{Cu}_{2} \mathrm{ZnSnS}_{4}$ thin films by pulsed laser deposition," Phys. Status Solidi, vol. 3 , no. 8, pp. 2618-2621, 2006.

[5] C. Persson, "Electronic and optical properties of $\mathrm{Cu}_{2} \mathrm{ZnSnS}_{4}$ and $\mathrm{Cu}_{2} \mathrm{ZnSnSe}_{4}$," J. Appl. Phys., vol. 107, no. 5, pp. 1-8, 2010.

[6] K. Ito and T. Nakazawa, "Electrical and optical properties of Stannite-type quaternary semiconductor thin films," Japanese J. Appl. Phys., vol. 27, no. 11, pp. 2094-2097, 1988.

[7] P. A. Fernandes, P. M. P. Salomé, A. F. Da Cunha, and B. A. Schubert, " $\mathrm{Cu}_{2} \mathrm{ZnSnS}_{4}$ solar cells prepared with sulphurized dc-sputtered stacked metallic precursors," Thin Solid Films, vol. 519, no. 21, pp. 7382-7385, 2011.

[8] J. Li et al., "Tailoring the defects and carrier density for beyond $10 \%$ efficient CZTSe thin film solar cells," Sol. Energy Mater. Sol. Cells, vol. 159, pp. 447-455, 2017.

[9] P. M. P. Salomé, H. Rodriguez-Alvarez, and S. Sadewasser, "Incorporation of alkali metals in chalcogenide solar cells," Sol. Energy Mater. Sol. Cells, vol. 143, pp. 9-20, 2015.

[10] P. K. Sarswat, M. Snure, M. L. Free, and A. Tiwari, "CZTS thin films on transparent conducting electrodes by electrochemical technique," Thin Solid Films, vol. 520, no. 6, pp. 1694-1697, 2012.
[11] P. K. Sarswat and M. L. Free, "A comparative study of co-electrodeposited $\mathrm{Cu}_{2} \mathrm{ZnSnS}_{4}$ absorber material on fluorinated tin oxide and molybdenum substrates," J. Electron. Mater., vol. 41, no. 8, pp. 2210-2215, 2012.

[12] P. K. Sarswat and M. L. Free, "An investigation of rapidly synthesized $\mathrm{Cu}_{2} \mathrm{ZnSnS}_{4}$ nanocrystals," J. Cryst. Growth, vol. 372, pp. 87-94, 2013.

[13] K. Tanaka, Y. Takamatsu, and S. Miura, "Chemical composition dependence of photoluminescence from $\mathrm{Cu}_{2} \mathrm{ZnSnS}_{4}$ thin films with potential fluctuations," Phys. Status Solidi, vol. 14, no. 6, 2017, Art. no. 1600138.

[14] J. Poortmans et al., "Progress in cleaning and wet processing for kesterite thin film solar cells," Ultra Clean Process. Semicond. Surf. XIII, vol. 255, pp. 348-353, 2016.

[15] M. Courel, E. Valencia-Resendiz, J. A. Andrade-Arvizu, E. Saucedo, and O. Vigil-Galán, "Towards understanding poor performances in spraydeposited $\mathrm{Cu}_{2} \mathrm{ZnSnS}_{4}$ thin film solar cells," Sol. Energy Mater. Sol. Cells, vol. 159, pp. 151-158, 2017.

[16] C. Platzer-Björkman et al., "Reduced interface recombination in $\mathrm{Cu}_{2} \mathrm{ZnSnS}_{4}$ solar cells with atomic layer deposition $\mathrm{Zn1-xSnxOy}$ buffer layers," Appl. Phys. Lett., vol. 107, no. 24, pp. 1-5, 2015.

[17] M. T. Winkler et al., "Optical designs that improve the efficiency of $\mathrm{Cu}_{2} \mathrm{ZnSn}(\mathrm{S}, \mathrm{Se})_{4}$ solar cells," Energy Environ. Sci., vol. 7, no. 3, pp. 1029 1036, 2014.

[18] I. Repins et al., "Co-evaporated $\mathrm{Cu}_{2} \mathrm{ZnSnSe}_{4}$ films and devices," Sol. Energy Mater. Sol. Cells, vol. 101, pp. 154-159, 2012.

[19] W. Wang et al., "Device characteristics of CZTSSe thin-film solar cells with 12.6\% efficiency," Adv. Energy Mater., vol. 4, no. 7, pp. 1-5, 2014.

[20] P. M. P. Salomé et al., "Secondary crystalline phases identification in $\mathrm{Cu}_{2} \mathrm{ZnSnSe}_{4}$ thin films: Contributions from Raman scattering and photoluminescence," J. Mater. Sci., vol. 49, no. 21, pp. 7425-7436, 2014.

[21] P. A. Fernandes, P. M. P. Salomé, and A. F. Da Cunha, "Growth and Raman scattering characterization of $\mathrm{Cu}_{2} \mathrm{ZnSnS}_{4}$ thin films," Thin Solid Films, vol. 517, no. 7, pp. 2519-2523, 2009.

[22] B. Vermang et al., "Rear surface optimization of CZTS solar cells by use of a passivation layer with nanosized point openings," IEEE J. Photovolt., vol. 6, no. 1, pp. 332-336, Jan. 2016.

[23] H. Xie et al., "Impact of $\mathrm{Sn}(\mathrm{S}, \mathrm{Se})$ secondary phases in $\mathrm{Cu}_{2} \mathrm{ZnSn}(\mathrm{S}, \mathrm{Se})_{4}$ solar cells: A chemical route for their selective removal and absorber surface passivation," ACS Appl. Mater. Interfaces, vol. 6, no. 15, pp. 12744 12751, 2014

[24] A. Kanevce, I. Repins, and S. H. Wei, "Impact of bulk properties and local secondary phases on the $\mathrm{Cu}_{2}(\mathrm{Zn}, \mathrm{Sn}) \mathrm{Se}_{4}$ solar cells open-circuit voltage," Sol. Energy Mater. Sol. Cells, vol. 133, pp. 119-125, 2015.

[25] R. Ahmad et al., "A comprehensive study on the mechanism behind formation and depletion of $\mathrm{Cu}_{2} \mathrm{ZnSnS}_{4}$ (CZTS) phases," CrystEngComm, vol. 17, no. 36, pp. 6972-6984, 2015.

[26] S. Garud et al., "Alkali assisted reduction of open-circuit voltage deficit in CZTSe solar cells," Phys. Status Solidi (C), vol. 14, no. 10, pp. 2-7, 2017.

[27] J. Kim, S. Park, S. Ryu, J. Oh, and B. Shin, "Improving the open-circuit voltage of $\mathrm{Cu}_{2} \mathrm{ZnSnSe}_{4}$ thin film solar cells via interface passivation," Prog. Photovolt. Res. Appl., vol. 25, no. 4, pp. 308-317, Apr. 2017.

[28] J. P. Teixeira et al., "Comparison of fluctuating potentials and donoracceptor pair transitions in a Cu-poor $\mathrm{Cu}_{2} \mathrm{ZnSnS}_{4}$ based solar cell," Appl. Phys. Lett., vol. 105, no. 16, Oct. 2014, Art. no. 163901.

[29] J. P. Teixeira et al., "Radiative transitions in highly doped and compensated chalcopyrites and kesterites: The case of $\mathrm{Cu}_{2} \mathrm{ZnSnS}_{4}$," Phys. Rev B, vol. 90 , no. 23 , Dec. 2014, Art. no. 235202.

[30] T. Gokmen, O. Gunawan, T. K. Todorov, and D. B. Mitzi, "Band tailing and efficiency limitation in kesterite solar cells," Appl. Phys. Lett., vol. 103, no. 10, Sep. 2013.

[31] C. J. Hages, N. J. Carter, and R. Agrawal, "Generalized quantum efficiency analysis for non-ideal solar cells: Case of $\mathrm{Cu}_{2} \mathrm{ZnSnSe}_{4}$," J. Appl. Phys., vol. 119, no. 1, 2016.

[32] T. Gershon et al., "Unconventional kesterites: The quest to reduce band tailing in CZTSSe," Curr. Opin. Green Sustain. Chem., vol. 4, pp. 29-36, 2017.

[33] J. J. S. Scragg et al., "Cu-Zn disorder and band gap fluctuations in $\mathrm{Cu} 2 \mathrm{ZnSn}(\mathrm{S}, \mathrm{Se}) 4$ : Theoretical and experimental investigations," Phys. Status Solidi Basic Res., vol. 253, no. 2, pp. 247-254, 2016.

[34] G. Rey et al., "The band gap of Cu2ZnSnSe4: Effect of order-disorder," Appl. Phys. Lett., vol. 105, no. 11, 2014.

[35] H. Katagiri et al., "Enhanced conversion efficiencies of $\mathrm{Cu}_{2} \mathrm{ZnSnS}_{4}$ based thin film solar cells by using preferential etching technique," Appl. Phys. Express, vol. 1, no. 4, pp. 0412011-0412012, 2008. 
[36] C. Wang et al., "Design of I2-II-IV-VI4 semiconductors through element substitution: The thermodynamic stability limit and chemical trend," Chem. Mater, vol. 26, pp. 3411-3417, 2014.

[37] M. Kumar, A. Dubey, N. Adhikari, S. Venkatesan, and Q. Qiao, "Strategic review of secondary phases, defects and defect-complexes in kesterite CZTS-Se solar cells," Energy Environ. Sci., vol. 8, no. 11, pp. 31343159, 2015.

[38] S. Ranjbar et al., "Effect of $\mathrm{Sn} / \mathrm{Zn} / \mathrm{Cu}$ precursor stack thickness on twostep processed kesterite solar cells," Thin Solid Films, vol. 633, pp. 127130, 2017.

[39] J. Li et al., "A temporary barrier effect of the alloy layer during selenization: Tailoring the thickness of $\mathrm{MoSe}_{2}$ for efficient $\mathrm{Cu} 2 \mathrm{ZnSnSe} 4$ solar cells," Adv. Energy Mater., vol. 5, no. 9, 2015, Art. no. 1402178.

[40] S. Bals, W. Tirry, R. Geurts, Z. Yang, and D. Schryvers, "High-quality sample preparation by low kV FIB thinning for analytical TEM measurements," Microsc. Microanal., vol. 13, no. 2, pp. 80-86, Apr. 2007.

[41] C. A. Volkert, A. M. Minor, and G. Editors, "Focused ion beam micromachining," vol. 32, pp. 389-399, 2007.

[42] T. Ishitani, K. Umemura, T. Ohnishi, T. Yaguchi, and T. Kamino, "Improvements in performance of focused ion beam cross-sectioning: Aspects of ion-sample interaction," J. Electron Microsc., vol. 53, no. 5, pp. 443449, 2004.

[43] L. A. Giannuzzi and F. A. Stevie, Eds., Introduction to Focused Ion Beams. Boston, MA, USA: Springer, 2005.

[44] C. Yan et al., "Boost VOC of pure sulfide kesterite solar cell via a double CZTS layer stacks," Sol. Energy Mater. Sol. Cells, vol. 160, pp. 7-11, 2017.

[45] S. W. Fu, H. J. Chen, S. H. Wu, H. T. Wu, and C. F. Shih, "Impact of prealloying of sputtered $\mathrm{Cu} / \mathrm{Sn} / \mathrm{Zn}$ precursors for $\mathrm{Cu}_{2} \mathrm{ZnSnS}_{4}$ thin films," Mater. Lett., vol. 173, pp. 1-4, 2016.

[46] H. J. Chen et al., "Impact of $\mathrm{SnS}$ buffer layer at $\mathrm{Mo} / \mathrm{Cu}_{2} \mathrm{ZnSnS}_{4}$ interface," J. Amer. Ceram. Soc., vol. 99, no. 5, pp. 1808-1814, 2016.

[47] J. J. Scragg et al., "Effects of back contact instability on $\mathrm{Cu}_{2} \mathrm{ZnSnS}_{4}$ devices and processes," Chem. Mater, vol. 25, no. 15, pp. 3162-3171, 2013.

[48] X. Fontań et al., "In-depth resolved Raman scattering analysis for the identification of secondary phases: Characterization of $\mathrm{Cu}_{2} \mathrm{ZnSnS}_{4}$ layers for solar cell applications," Appl. Phys. Lett., vol. 98, no. 18, pp. 4-6, 2011.

[49] S. Sahayaraj et al., "Doping of $\mathrm{Cu}_{2} \mathrm{ZnSnSe}_{4}$ solar cells with $\mathrm{Na}^{+}$or $\mathrm{K}^{+}$ alkali ions," J. Mater. Chem. A, vol. 6, pp. 2653-2663, 2018.

[50] Y.-C. Lin, L.-C. Wang, K.-T. Liu, Y.-R. Syu, and H.-R. Hsu, "A comparative investigation of secondary phases and $\mathrm{MoSe}_{2}$ in $\mathrm{Cu}_{2} \mathrm{ZnSnSe}_{4}$ solar cells: Effect of Zn/Sn ratio," J. Alloys Compd., vol. 743, pp. 249-257, Apr. 2018.
[51] Y. Wei et al., "An investigation on phase transition for as-sputtered $\mathrm{Cu}_{2} \mathrm{ZnSnSe}_{4}$ absorbers during selenization," Sol. Energy, vol. 164, pp. 5864, Apr. 2018.

[52] R. Sun et al., "Beyond $11 \%$ efficient $\mathrm{Cu}_{2} \mathrm{ZnSn}(\mathrm{Se}, \mathrm{S})_{4}$ thin film solar cells by cadmium alloying," Sol. Energy Mater. Sol. Cells, vol. 174, pp. 494 498, Jan. 2018

[53] J. M. Cairney and P. R. Munroe, "Redeposition effects in transmission electron microscope specimens of FeAl-WC composites prepared using a focused ion beam," Micron, vol. 34, no. 2, pp. 97-107, 2003.

[54] C. Lehrer, L. Frey, S. Petersen, and H. Ryssel, "Limitations of focused ion beam nanomachining," J. Vac. Sci. Technol. B Microelectron. Nanometer Struct., vol. 19, no. 6, 2001, Art. no. 2533.

[55] J. C. Gonzalez, D. P. Griffis, T. T. Miau, and P. E. Russell, "Chemically enhanced focused ion beam micromachining of copper," J. Vac. Sci. Technol. B Microelectron. Nanometer Struct., vol. 19, no. 6, pp. 2539-2542, 2001

[56] J. C. Gonzalez, M. I. N. da Silva, D. P. Griffis, and P. E. Russell, "Improvements in focused ion beam micromachining of interconnect materials," J. Vac. Sci. Technol. B Microelectron. Nanometer Struct., vol. 20, no. 6, 2002, Art. no. 2700.

[57] W. Li, J. Chen, C. Yan, F. Liu, and X. Hao, "Transmission electron microscopy analysis for the process of crystallization of $\mathrm{Cu}_{2} \mathrm{ZnSnS}_{4}$ film from sputtered $\mathrm{Zn} / \mathrm{CuSn}$ precursor," Nanotechnology, vol. 25, no. 19, 2014, Art. no. 195701.

[58] S. Bag, O. Gunawan, T. Gokmen, Y. Zhu, and D. B. Mitzi, "Hydrazineprocessed Ge-substituted CZTSe solar cells," Chem. Mater, vol. 24, no. 23, pp. 4588-4593, 2012.

[59] K. Woo et al., "Band-gap-graded $\mathrm{Cu} 2 \mathrm{ZnSn}(\mathrm{S} 1-x$, Sex 4 solar cells fabricated by an ethanol-based, particulate precursor ink route," Sci. Rep., vol. 3, no. 1, 2013, Art. no. 3069

[60] J. W. Cho et al., "Synthesis of $\mathrm{Cu}_{2} \mathrm{ZnSnS}_{4}$ thin films by a precursor solution paste for thin film solar cell applications," ACS Appl. Mater. Interfaces, vol. 5, no. 10, pp. 4162-4165, 2013.

[61] B. G. Mendis et al., "Nanometre-scale optical property fluctuations in $\mathrm{Cu}_{2} \mathrm{ZnSnS}_{4}$ revealed by low temperature cathodoluminescence," Sol. Energy Mater. Sol. Cells, vol. 174, pp. 65-76, 2018.

Authors' photographs and biographies not available at the time of publication. 